Check for updates

Vancouver Island

Cite this as: $B M J 2021 ; 373: n 1133$ http://dx.doi.org/10.1136/bmj.n1133 Published: 04 May 2021

\title{
Covid-19: Uptake of testing does not reflect chances of positive test, study finds
}

\section{Barbara Kermode-Scott}

Social determinants of health and certain health conditions are associated with testing and with testing positive for SARS-CoV-2, a study published in the Canadian Medical Association Journal has found.

And it is important to understand these factors in managing the response to the pandemic, the researchers suggest, after they conducted an observational study using cross sectional analyses among nearly 14.7 million community dwelling people in Ontario, Canada.

Researchers analysed data on 14695579 people in Ontario from March to June 2020, of whom 758691 were tested for SARS-CoV-2 and 25030 (3.3\%) tested positive.

The research team explored the potential for collider or selection bias and characterised individual, environmental, and social determinants of being tested and of testing positive for SARS-CoV-2 infection.

"Having certain underlying health conditions, like asthma and chronic obstructive pulmonary disease, increased the likelihood of being tested for SARS-CoV-2 even though those conditions were not related to an increased risk of testing positive," said the lead author, Maria Sundaram of the Institute for Clinical Evaluative Sciences. "This indicates the potential for selection bias in population level epidemiological studies of covid-19."

\section{Comorbidities}

Having the flu vaccine in the 2019-20 season was associated with reduced odds of a positive test result for SARS-CoV-2, while older age and certain comorbidities-such as hypertension, diabetes, congestive heart failure, dementia, chronic kidney disease, and ischaemic stroke or transient ischaemic attack, as well as increased previous use of healthcare-were associated with increased odds of a positive test result.

Certain social determinants of health were consistently related to an increased risk of testing positive, including residing in areas with the highest household density (adjusted odds ratio 1.86 (95\% confidence interval 1.75 to 1.98)), essential work status (1.58 (1.48 to 1.69)), lower educational attainment (1.33 (1.26 to 1.41)), and recent immigration status (1.10 (1.05 to 1.15)).

The authors noted little association, however, between most social determinants and the odds of being tested. They hypothesised, therefore, that testing resources may not be adequately prioritising the people at the highest risk of contracting SARS-CoV-2.
"The biggest takeaway from this research, for me, is how inequity is influencing both the covid-19 pandemic and potentially also our science," said Sundaram. "We see big potentials for misclassification bias because of inequity regarding access to testing. And perhaps even more striking is that we see these consistent relationships between covid-19 and social determinants of health, no matter what study design we chose to try to mitigate this.

"To me, this means that failing to address inequity, or addressing it only by half measures, will result in a prolonging of the pandemic as well as biases in covid-19 epidemiology."

Effective responses to covid-19 require that the social determinants associated with access to testing and SARS-CoV-2 transmission risks be characterised and tackled using risk tailored, community based interventions, the authors concluded.

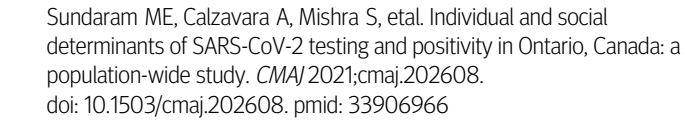

This article is made freely available for use in accordance with BMJ's website terms and conditions for the duration of the covid-19 pandemic or until otherwise determined by BMJ. You may use, download and print the article for any lawful, non-commercial purpose (including text and data mining) provided that all copyright notices and trade marks are retained. 